\title{
CREDIT TRANSFER, ARTICULATION \& THE FUTURE OF WORK: TOWARDS A FEDERAL STRATEGY
}

\author{
ROGER PIZARRO MLLIAN \\ UNIVERSITY OF TORONTO
}

\author{
YVETTEMUNRO \\ YORK UNIVERSITY
}

\begin{abstract}
Some analysts foresee that the rise of automation-triggered by advances in artificial intelligence, robotics, and other novel technologies-will soon unsettle sizable sections of our labour market, prompting the need for mass upskilling and re-skilling. Continuous learning is perceived as the new norm within the future of work. Many believe that solutions to future surges in training demand will require a degree of dexterity not exhibited by traditional postsecondary education (PSE) organizations, and advocate for radical alternatives. However, we outline how basic reforms leading to a more robust articulation and credit transfer system could also improve our PSE system's ability to handle augmented training demands. In turn, we explore how the Canadian federal government can facilitate these reforms by (a) providing additional incentives for domestic colleges and universities to engage in seamless transfer, and (b) supporting the production of knowledge to inform more strategic forms of pathway articulation.

Keywords: transfer credit, articulation, future of work, policy
\end{abstract}

\section{Résumé}

Des analystes prévoient que la hausse de l'automatisation, stimulée par les progrès de l'intelligence artificielle, de la robotique et d'autres technologies novatrices, va bientôt déstabiliser des segments importants du marché du travail, entraînant une vague de mises à niveau et de requalifications. L'apprentissage continu est considéré comme la nouvelle norme pour le marché du travail de l'avenir. Nombreux sont ceux qui croient que la future croissance de la demande en formation nécessitera un degré de dextérité jusqu'ici non démontré par les établissements d'enseignement postsecondaire traditionnels, et qui préconisent des solutions de rechange radicales. Néanmoins, nous suggérons que des réformes de base pour consolider le système d'articulation et de transfert de crédits pourraient également améliorer la capacité de notre système d'enseignement postsecondaire à prendre en charge des demandes de formation accrues. Ensuite, nous explorons comment le gouvernement fédéral canadien peut faciliter ces réformes i) en offrant des incitatifs supplémentaires aux collèges et universités du pays pour qu'ils offrent des passerelles plus fluides; et ii) en soutenant le développement des connaissances pour trouver des options d'articulation des parcours qui soient plus stratégiques.

Mots-clés : transfert de crédits, articulation, avenir du travail, politique

\section{Introduction}

An entire genre of industry white papers, policy reports, and academic studies has emerged over the last decade to warn us about looming disturbances to our labour markets as a function of technology-enabled automation (e.g., Arntz et al., 2016; Frey \& Osborne, 2017; Labour Market Information Council, 2019; Organisation for Economic Co-operation and Development [OECD], 2020).
Some believe that just under half of all jobs in Canada may be at risk of disruption (Lamb, 2016). More broadly, some analysts believe that between 400 and 800 million workers will be displaced by 2030 (Manyika et al., 2017). This perceived threat is driving governments around the world to brace for impact. ${ }^{1}$ The Canadian federal government responded in part in 2019 by investing over $\$ 300$ million into a Future Skills Centre (FSC) that will forecast future skills needs and evaluate innovative 
training strategies. A review of projects funded during the FSC's inaugural year reveals little faith in the capacity of colleges and universities to meet future skills needs on their own, with many including a mixture of industry groups, unions, quasi-governmental networks or community organization partners. This inter-sectoral, collaborative approach to skills development is consistent with the view that colleges and universities may be too rigid to effectively respond to dynamic labour market needs (see Cukier, 2019), and that employers will need to play a more significant role in workforce training (Desire to Learn, 2018, p. 7; OECD, 2019, p. 15; Schwab \& Samans, 2016, p. v).

Despite the growing excitement with these innovative initiatives, we posit that more basic reforms can also go a long way towards priming Canadian PSE to meet surges in training needs that are projected to be increasingly common in the future of work literature. In particular, we believe a more seamless credit transfer system can significantly reduce time-to-completion for displaced workers returning to PSE for upskilling or re-skilling. This would have the effect of expediting human capital production while also reducing the financial costs of such a process on students and government. In line with this special issue's thematic focus, throughout this piece we identify concrete ways in which the Canadian federal government can collaborate with provincial counterparts on this matter. In particular, we believe that they can provide an additional layer of incentives to promote PSE organizations' compliance with existing inter-provincial statements on best transfer practices; support for the development of more robust data-infrastructure and tracking of transfer performance, and facilitate cross-sector consultations to inform more strategic forms of articulation.

These specified reforms received zero attention during the most recent federal elections, and are unlikely to do so in the future, due to the humdrum feel of fundamental reforms in PSE vis-à-vis the allure of more flashy calls for radical disruption. However, we believe that they constitute a relatively prudent set of tactics, well within reach, to improve Canadian PSE's capacity to handle future training challenges. Indeed, they could be perceived as complementary to the more radical calls for new micro-credentials or forms of training delivery. Our recommendations, though national in scope, are rooted in our knowledge of and experiences within Ontario PSE, and thus, may not reflect the views of counterparts in other provinces. Our recommendations are further informed by our understanding of transfer research, policy innovations, and mechanisms in the United States-a nation that has had a much longer affair with transfer than most Canadian provinces. We hope that this eclectic piece will spark national conversations about credit transfer and articulation that are inclusive of stakeholders at multiple levels - including institutional representatives (e.g., Colleges and Institutes Canada, Universities Canada), provincial and federal policymakers, councils on articulation and transfer (CATs) and other groups (e.g., Council of Ministers of Education, Canada).

\section{A Brief Primer on Credit Transfer and Articulation}

Credit transfer refers to the process through which student learning at one PSE organization is formally recognized by another. Ideally, when students change schools, they receive full recognition for all prior, relevant learning. Natural exceptions to this include previous credits earned in courses where technologies or skills have since changed significantly since a course was completed (e.g., health care, information technology). Or, where prior learning is in a low-affinity area which does not translate into a new credential (e.g., welding to English). Full or optimal credit recognition wards against the unnecessary repetition of courses, allowing students to graduate and enter the labour force in a timely fashion, and produces cost-savings for both students (e.g., tuition, opportunity costs) and governments (see Snowdon \& Brady, 2014; Trick, 2013). However, in practice, many transfer students experience credit loss due to various reasons (Jenkins \& Fink, 2015; Monaghan \& Attewell, 2015; Simone, 2014). There are, as previously mentioned, those who lose credits by virtue of transferring between low-affinity programs. However, scholars also suggest that a university culture that has traditionally viewed college education, students and faculty as being of lower quality, or "inferior goods" (Dowd \& Melguizo, 2008 , p. 395), also hampers full credit recognition for college-to-university transfers (Gerhardt \& Masakure, 2016, p. 81; Ignash, 1992; Fincher, 2002).

Articulated pathways-consisting of formalized bior multi-lateral agreements between PSE institutionscan limit the extent of credit loss during transfer (Roksa $\&$ Keith, 2008). The American 2+2 model is arguably the most popular, or at least coveted, type of articulated 
pathway, and one that has attracted the attention of a few Canadian jurisdictions (Brown, 2016; Trick, 2013). It theoretically allows students to complete a 2-year associate degree at a community college, with subsequent completion of a 4-year baccalaureate degree occurring after the equivalent of two additional years of full-time study at a university. ${ }^{2}$ Articulation can also exist at a much smaller scale, through an array of course-level equivalencies that allow students to carry a smorgasbord of credits that may not fit within the narrow confines of a $2+2$ pathway. Along this continuum of transfer models ranging from the $2+2$ model to the more random assortment of course equivalencies sits an array of other arrangements, whereby a smaller block of courses, be it a single year or other grouping of courses, can be transported without loss across a PSE system (Trick, 2013).

\section{The State of Transfer in Canada}

Several reviews of transfer and student mobility in Canada have been published since the turn of the century (CMEC, 2012; Heath, 2012; Junor \& Usher, 2008). They generally conclude that progress towards seamless transfer in Canada is uneven. This is unsurprising given that PSE in the Canadian political system, along with credit transfer and articulation, falls under provincial rather than federal jurisdiction (Eastman et al., 2019). As such, each province has been afforded the autonomy to craft its own solutions to improve intra-provincial student mobility. Two commonly acknowledged leaders in this space are Alberta and British Columbia, ${ }^{3}$ where significant inroads have been made over the decades towards unimpeded transfer. Beyond these two provinces, the situation for transfer students varies widely, and is at times unclear or bleak. Contrasting jurisdictions (e.g., British Columbia) where coordinating mechanisms such as Councils on Articulation/Admission and Transfer (e.g., CATs) and government policies have been in place for decades are those (e.g., Ontario) where such structures have only emerged in recent history. Students in these less mature or emergent provincial transfer systems face great uncertainty about the amount of transfer credit they will receive, especially when they cross sector lines (e.g., college-to-university). In Ontario, for example, articulated college-to-university pathways typically do not conform to the $2+2$ model, with only approximately 120 of such pathways listed in the provincial ONTransfer.ca database (Ontario Council on Articulation and Transfer [ONCAT], 2020). As a result, transfer students typically experience longer time to completion (e.g., $2+3,2+3.5$ ) than their direct entry counterparts. Moreover, in Ontario, little effort has also been made to develop formal pathways crossing public-private lines (e.g., with private career colleges or universities). Indeed, the latter are ineligible to receive funding from ONCAT for pathway building or research.

\section{Inter-Provincial Statements on Credit Transfer and Articulation}

Though PSE and transfer fall under provincial jurisdiction, we have seen several efforts by the Council of Ministers of Education, Canada (CMEC, 1995, 2002)—an inter-provincial entity-to promote unfettered student mobility across the country. First, in 1995, CMEC published a pan-Canadian protocol establishing the transferability of all first- and second-year university courses. This protocol was signed by every province (Arnold, 2011), approved by the board of directors of the Association of Universities and Colleges of Canada (now Universities Canada), endorsed by some provincial university associations (Monahan, 2004), and passed by the senate of numerous universities (for examples, see University of Guelph, 1996; York University, 1995). Then, in 2002, CMEC published its Ministerial Statement on Credit Transfer in Canada, laying out broader principles that should govern how both colleges and universities perform transfer, aiming for greater consistency and transparency. Though signed by all provinces, there is no evidence that either document translated into notable improvements even in directly relevant areas. For example, the CMEC ministerial statement sets out that students should have complete information on available transfer opportunities. The extent to which this has been accomplished is questionable. Several provinces have transfer guides with information about articulation agreements and course equivalencies, but the quality of this information is unclear. In Ontario, for example, neither ONCAT nor the provincial government has the power to force PSE organizations to submit course equivalency and block transfer agreement information onto the ONTransfer.ca database. As a result, transfer credit information can at times be publicly unavailable, outdated, or incomplete. ${ }^{4}$ 


\section{Transfer, Articulation, and Skills Development}

The inefficacy of CMEC statements is due in part to the absence of policy coordination and accountability mechanisms, and contrasts progress made in other countries towards ensuring the transferability of credits and availability of clear protocols to guide organizational behaviour (Duklas, 2014). For example, the European Credit Transfer and Accumulation System (ECTS) is used by many countries in that continent to support student mobility within and among participating jurisdictions. In Canada, the lack of a national strategy perpetuates a fragmented approach (Trick, 2013). This is unfortunate given that, as we illustrate below, and as several organizations and scholars have persuasively argued over the years (see Álvarez-Galván et al., 2015; Field \& Kuczera, 2012; Fazekas \& Field, 2013; Field et al., 2014; PhillipsKPA, 2006; OECD, 2010, 2012, 2014), a more efficient credit transfer and articulation system enables more expedient training, and provides a tool through which to overcome the projected challenges brought on by the future of work. Hidden in plain sight, transfer remains overlooked as a tool to improve individual educational achievement and regional economic development (Handel \& Strempel, 2016, p. ix).

Efficient transfer and articulation serve as a solution for a fundamental problem in PSE. Deep fault lines exist between sectors (e.g., college/university) across many PSE systems, serving as artificial barriers that (i) hinder student access to training opportunities at subsequent credential tiers, and (ii) elongate program completion time once a student achieves access. Such fault lines have the effect of dis-incentivizing human capital development at both the individual and macro-level (OECD, 2010, p. 16). In segmented systems such as these, articulated pathways can serve as a bridge over such barriers, allowing workers to enter programs and expediently acquire the skills they need to re-enter the workforce. Articulated pathways do so by reducing the opportunity costs that accompany further education, especially for older workers seeking additional training for workforce re-entry (see Lamb et al., 2019, p. 17). Below, we outline how these pathways can aid in facilitating both upskilling and re-skilling efforts commonly associated with the future of work.

\section{Upskilling}

Analysts predict that technological change will prompt many individuals to return to PSE to upskill, seeking more advanced training to keep up with market demand (e.g., Manyika et al., 2017). Here, articulated pathways could play a vital role in the expedient training of these individuals (Álvarez-Galván et al., 2015). Consider the hypothetical case of an individual with a 2-year college diploma in computer programming, who is sponsored by their employer to engage in professional development after several years on the job. A mature articulation system would allow vertical transfer into higher credentials, allowing them to complete a bachelor's degree in the same general field (e.g., software engineering) with the equivalent of approximately two additional years of full-time study. Even when pursued on a part-time basis, given that mature transfer students may be employed and/or less likely able to pursue full-time education, the completion of the equivalent of two additional years is more manageable and less disruptive than completing another postsecondary credential without any transfer credit. This pathway would unlock the next tier of technical skills and provide access to graduate-level training offering skills that are even more advanced. Second, a sophisticated system would also allow for lateral transfer, within the same credential tier, into related specializations within information technology (e.g., cybersecurity, web development), as well as facilitate access to management credentials with some degree of affinity to the hypothetical programmer's industry and job-function (e.g., IT management, network administration).

Several principles could guide the efficient processing of this hypothetical programmer. First, regardless of the direction they move in, they should be exempted from repeating coursework focusing on knowledge (e.g., Python, Java) already covered in previous credentials. Second, previously completed elective courses should be applied indiscriminately towards any such requirements in their next program. Lastly, this hypothetical programmer may have completed professional training that is either not formally credentialed (e.g., coding boot camps, hackathons) or certified in ways not usually considered equivalent to colleges/university courses (e.g., badges, industry certifications). ${ }^{5} \mathrm{~A}$ robust credit transfer system would recognize such a branch of alternative training options, and exempt our hypothetical programmer from unnecessarily repeating this learning when 
seeking another degree. The overarching goal here would be to reduce unnecessary course duplication and fast-track labour force re-entry.

Moving beyond this hypothetical is a second more empirically-grounded example that illustrates the potential for transfer to promote upskilling at mass scale. Near completers are individuals who have earned a considerable number of course credits but have not earned a formal credential (National Student Clearinghouse Research Center, 2019). Often, this group struggles with both under- and unemployment-relative to completers (see Giani et al., 2019)-given the centrality of credentials in labour market matching (Rivera, 2011). But, near completers can be expediently upskilled to fill positions in many high-demand industries. In the U.S., this group has been strategically targeted by state policymakers through an array of initiatives that embrace robust credit transfer policies. In states such as Indiana, Mississippi, and Tennessee, legislation (a) established frameworks for data sharing and utilization to identify near completers; (b) coordinated and branded state-wide outreach strategies (e.g., "Complete to Compete"); (c) and created responsive student financial aid strategies (e.g., loan forgiveness). Targeting near completers allows professionals to be produced far more expediently and cost-effectively than training high school graduates from scratch. There is every indication that Canada has many of these near completers within its borders. In our home province, we know that public colleges have graduation rates just under the $70 \%$ mark (Ontario Ministry of Colleges and Universities, 2019). Meanwhile, degree completion rates at universities range widely from $60-80 \%$ (Council of Ontario Universities, 2020). Upskilling students who fall just short of graduation through arrangements that give them full credit recognition is a strategy that would be worth piloting north of the border. We fathom that it would be particularly useful for improving the completion rates of traditionally marginalized groups, who tend to be overrepresented among school leavers.

\section{Re-Skilling}

Several types of articulated pathways could also facilitate the efficient re-training of laid-off workers whose jobs may have been wiped out by technology-enabled automation. Consider a second hypothetical scenario: that of an individual with a 2-year general business diploma that has been laid off from a sales job. When this individual returns to PSE, they should be similarly afforded a set of re-training opportunities that recognize and build upon prior formal learning. For example, vertical pathways should be available for them to further specialize in other branches of business, of which they may have only minimal knowledge and experience in, perhaps including accounting, advertising, human resources, or marketing. Such pathways could allow this hypothetical individual to re-enter the labour market via many occupations, and potentially industries, that differ widely from their previous role. Ideally, these pathways would abide by the $2+2$ model, allowing this hypothetical individual to complete a bachelor's degree with the equivalent of only two years of additional full-time study.

Admittedly, this hypothetical consists of a relatively minor career shift, requiring student movement across relatively high-affinity areas-those with a standard set of overlapping courses (e.g., intro to business) during the first two years of study. Theoretically, such career shifts would require minimal re-training to begin with, given that core knowledge necessary for the jobs they prepare students for exhibit overlap (Lamb et al., 2019, p. 17). This may leave some asking: can credit transfer help a more radical shift across low-affinity fields or labour market segments? Could they help individuals whose academic specialization is entirely rendered redundant by technological change? The answer is yes, to the extent that articulated pathways can shorten the time to completion for students seeking second credentials. Ryerson University provides a template for how this could be achieved at a much broader level within Canadian PSE. Ryerson currently allows graduates of any bachelor's degree from another university, regardless of their field of study, to complete a second bachelor's in Occupational Health \& Safety or Public Health with only two additional years of full-time study. This is a promising model that could be used to facilitate the expedited completion of credentials across other in-demand areas (e.g., STEM), especially if there is a concerted push and incentives for PSE organizations to develop such pathways.

\section{Federal Government's Potential Role}

Having outlined the prospective utility of a seamless transfer system for training efficiency, we move now to discuss the role that the federal government could play in promoting the emergence of said system. We foresee it playing two primary functions. First, it can (a) 
promote compliance with the principles contained in existing CMEC statements, to which all provinces are signatories; and (b) measure broader transfer-related performance at multiple levels. Second, it can gather and disseminate knowledge of what the most economically rewarding pathways are, which could factor into more strategic articulation decisions or pathway planning. We address each of these topics below.

\section{Promoting Compliance with CMEC Statements and other Best Practices}

The federal government can provide critical incentives for Canadian colleges and universities to better align practices with existing CMEC statements. A first step towards achieving this could be to engage CMEC, or another existing organization in the field with subject matter expertise-such as the Pan-Canadian Consortium on Admissions \& Transfer (PCCAT) - to gather information and monitor college and university adherence to existing CMEC principles. In addition, and as a strategy to ward against efforts to game this system, we believe the federal government could request that another independent entity-such as the Future Skills Centreempirically track broader organizational credit transfer performance using a parallel set of metrics. As McCloy et al. (2017) note, "a lack of system-wide data on the volume of movement between sectors...and their success after transfer" has been a crucial hurdle to examining the efficiency of transfer in provinces like Ontario ( $p$. 9). However, this tracking has become possible-albeit with a significant time lag-through Statistics Canada's Postsecondary Student Information System (PSIS) dataset. On the sending side, the PSIS allows one to identify which PSE organizations have the highest out transfer rates, and track the success (e.g., graduation rates, time to completion) of their students by pathway type (e.g., reverse, lateral), net of student demographics and receiving institution characteristics. These metrics would be particularly useful for colleges, which tend to be the proto-typical sending institutions in Canadian PSE. On the receiving side, the PSIS contains data fields, such as the number of transfer credits awarded, that can be leveraged to assess both leaders and "laggards" when it comes to awarding transfer credit, as well as other student success metrics. Statistics Canada does not currently recommend the use of some of these metrics for analysis, due to spotty coverage across provinces and sectors. Hence, improvements would have to be made to reporting procedures on the part of PSE organizations and other entities (e.g., provincial ministries) involved in the PSIS reporting process.

The federal government can leverage this data in several ways to promote organizational change as it pertains to transfer in Canadian PSE. A straightforward approach would be for the federal government to mandate an existing entity to collate and publish data on each organization and province's transfer performance, allowing for comparisons to be made by interested readers. A more assertive version of this approach would entail the production and active promotion of an annual transfer performance ranking of Canadian PSE organizations. This could trigger some degree of "reactivity" (Espeland \& Sauder, 2007) among PSE organizations, in the same way as the existing Maclean's or Globe and Mail rankings currently shape organizational behaviour. An even more heavy-handed, but admittedly more complicated and highly disruptive approach, to promote adherence to principles contained in CMEC statements and incentivize transfer performance, would be to render them prerequisites for accessing federal research funds available through the tri-council agencies, including $\mathrm{CIHR}$, NSERC, and SSHRC. This is a strategy that has been proposed before in the Ontario context as it pertains to the province's differentiation policy framework (see Pizarro Milian, 2018), and whose potential efficacy is based on tenets derived from organizational theory (Coburn, 2004; Oliver, 1991). Organizations are simply more likely to comply with external demands when multiple actors in their environment relay consistent pressures. It is also important to note that access to these funds is already conditional on PSE organizations meeting specific criteria set out by federal agencies, and following tri-council research ethics policies (e.g., Schoenherr \& Williams-Jones, 2016). As such, placing additional requirements for accessing these funds would not be a radical deviation from established practice. In sum, through this tenacious approach, the federal government could augment the work of provincial governments in nudging generally autonomous PSE organizations towards accepting a more progressive stance towards transfer.

\section{Informing Strategic Articulation}

Beyond promoting compliance with CMEC principles, the federal government can play an important role in producing knowledge to guide more strategic articulation. This is especially true as it pertains to ensuring that artic- 
ulated pathways are aligned with current and predicted labour market needs. To do so, it can work more closely with provincial governments to improve their tracking of graduate labour market outcomes and facilitate discussion between PSE and industry.

Improved Graduate Tracking. At the time of writing, there is relatively little research on labour market outcomes of Canadian transfer students (for an exception to this, see Finnie et al., 2020), even in provinces with the most advanced data infrastructure. Mainly, this is due to the absence of a link between student-level data stored in provincial Ministries and federal tax data (Weingarten et al., 2019). Improved longitudinal tracking capabilities with such linked data would allow for the identification of the most economically rewarding pathways for various types of transfer students, especially those from low-achieving groups. This knowledge could enable provincial Ministries and councils to incentivize the articulation of such pathways over less economically rewarding ones. Hypothetically, let us assume that transfers from college to university business programs enjoyed a hefty earnings premium, but those within the social sciences did not experience any tangible economic benefits. This could serve as a data point to guide the expenditure of the limited resources available to build pathways on the part of both PSE organizations, articulation councils, and provincial governments.

The abovementioned tracking of graduate outcomes is already possible (in part) through Statistics Canada's Education and Labour Market Longitudinal Platform (ELMLP) linkage platform, where the PSIS can be linked to a host of other federal administrative datasets, such as T1 Family Files (T1FF), and National Graduates Survey (NGS). These linkages have already been leveraged by Statistics Canada over the last few years to perform several sophisticated analyses of student success and labour market outcomes (Frenette, 2019a, 2019b). Using the ELMLP to track student outcomes would have significant advantages over graduate surveys performed in some provinces, which currently do not follow basic conventions in survey research. ${ }^{6}$ The PSIS avoids such pitfalls by providing census-like coverage of students and graduates, and also prevents the pitfalls of longitudinal surveys like the Youth in Transition Survey, which suffer from high levels of attrition.

One key additional improvement that could be made to the ELMLP_to bring it up to par with more advanced data infrastructure in several American states (e.g., Florida, Texas)-would be its linkage to student-level data from each provincial ministry managing $\mathrm{K}-12$ education (as has been done in B.C.), along with other relevant data sources from adjacent ministries. In Florida, for example, 27 datasets are linked within their education data warehouse (see Office of Program Policy Analysis \& Government Accountability, 2009). This includes data from the K-12 system, including grade school standardized tests in math, reading, writing and science, school grades and course schedule, student demographics, and staff and facility data. It also includes PSE-level data on student financial aid, demographics, course load, credit hours, and program of study, as well as staff data. Such data can be linked to information on graduate earnings, employment rates, industry location, continuing education, as well as incarceration and social assistance use. Many of these data fields would exceed the scope of most traditional analyses of transfer student outcomes. However, a more refined version of this infrastructure would be extremely useful for planning purposes across Canadian provinces.

Interestingly, the construction of Florida's data warehouse, along with numerous other American states, has been financially supported by the Statewide Longitudinal Data Systems Grant Program (SLDS), run by the Institute of Education Sciences (IES), which is the research and evaluation wing of the federal U.S. Department of Education. The IES, through its National Center for Education Statistics, publishes reports capturing transfer rates and trends, transferability of credits, and transfer student outcomes. As such, there is a strong precedent for the Canadian federal government to play a role in supporting the enhancement of provincial longitudinal data infrastructure and reporting.

Convening Industry-PSE Discussions. The overarching goal of articulation in Canada is to develop pathways between PSE organizations in a way that minimizes credit loss for students. As we have argued above, this focus is obviously beneficial, in that it reduces time-to-completion. However, there are also other factors that should be considered during this process. In particular, the OECD (2019) proposes that it is vital to engage employers and other stakeholders during systems planning to ensure that arrangements correspond with labour market needs. In Australia, consultations with "industry stakeholders to identify and trial new pathways mod- 
els" have been trialed in recent decades (Ithaca Group, 2018, p. 138; NSW Business Chamber, 2010). There, it has been proposed that these consultations allow:

...Industry Skills Councils, employer organisations, professional accreditation bodies and employers themselves to identify the skills they require of graduates and facilitate partnerships between VTE and higher education providers in order to produce graduates with the desired skill mix. (PhillipsKPA, 2006, p. 10)

Such recognition of the role that industry can play during articulation has given rise to multiple models. First is a 3-dimensional model (see Byrnes et al., 2011; Paez et al., 2011), whereby industry representatives are embedded as equal partners into articulation committees. However, there has also been discussion of industry-determined articulation pathways, which entails consulting with industry to ascertain what pathways would meet their current and predicted skill demands (Byrnes et al., 2011). Once such knowledge has been gathered, interested training providers would be brought on to develop solutions to meet such needs. Incorporating industry groups into the articulation process has the added benefit of reducing the odds that produced pathways run counter to established accreditation frameworks, especially in regulated professions like accounting and engineering (PhillipsKPA, 2006).

While embedding industry representatives into articulation committees could be quite burdensome, we imagine an arrangement whereby the federal government works with established industry groups-such as the Canadian Chamber of Commerce, Business Council of Canada, or the Business + Higher Education Roundtable-to convene cross-sector discussions to identify how present and looming skills needs could be met through strategically articulated pathways. The idea being that pathways through these two sectors can be designed to allow students traveling them to absorb an optimal combination of skills desired by industry. This could usefully inform not just decision-making in PSE organizations, but also, on the part of vocationally-minded students seeking an industry-endorsed pathway. Returning to our hypothetical computer programmer discussed earlier (see section on upskilling, paragraph one), companies that employ such individuals could advise colleges and universities on the types of pathways that should be developed to upskill such individuals. Perhaps, from the standpoint of employers, a pathway from a 2-year to 3-year college diploma would be more appealing than into a 4-year B.A. degree. Gathering such insights would be useful to engage in more labour market-oriented articulation. Colleges and universities in Canada already work with industry to ensure that their programs adequately prepare graduates, but there is little co-operation between these entities as it pertains specifically to articulation. This sort of industry input could complement more objective indicators of the economic returns to pathways, especially when it comes to anticipated or evolving needs.

\section{Conclusion}

Predictions about the future of work have promoted vigorous debate about the steps required to meet future training needs, both in Canada and abroad. In response to bold prophecies about disruption, many radical reforms to PSE, and education more broadly, have been suggested. We draw attention to how basic improvements to credit transfer and articulation can boost our domestic PSE system's ability to meet looming demands for upskilling and re-skilling, and perhaps complement more radical proposals. In turn, we outline how the federal government could help to make a more robust credit transfer and articulation system a reality. Primarily, we see the federal government as being in an ideal position to provide additional incentives and strategic coordination to improve adherence to existing CMEC agreements on transfer, and to produce information to guide continuous improvement of transfer functions and more strategic forms of articulation.

Despite our enthusiasm for the specified reforms, and the prospective role that the federal government could play in the promotion of a more robust transfer system, we are under no illusion that they are a panacea. First, we acknowledge that our invitation for more federal intervention might not be welcomed by provincial/territorial governments given their constitutional responsibility for PSE (see Shanahan \& Jones, 2007), and the historical "tensions" that have arisen in this forum between levels of government (Cameron, 2001; Jones, 2018). However, we believe that there is a clear intersection of the federal government's interests in the country's economic development and global competi- 
tiveness-matters that do fall within their jurisdictionand PSE. Moreover, there is a long track record of federal involvement in skills development, research funding and student financial assistance (Eastman et al., 2019; Shanahan \& Jones, 2007) that serves as clear precedent for their involvement in credit transfer. Carefully examining the institutional arrangements through which the federal government has historically been able to provide support and leadership in such spaces could help future scholars to theorize how their involvement in transferto address the upskilling and re-skilling needs of large pools of displaced workers-could play out. Unfortunately, sketching out a more comprehensive implementation plan for these recommendations is beyond the scope of this piece but we offer ideas, including some provocative ones, to spark a re-imagining of what might be possible. We acknowledge that drafting an effective plan, or even initiating the conversation, would require extensive consultation in order to determine an arrangement that would be efficient in its performance of the tasks we have outlined, reduce the likelihood of unintended negative consequences, and be respectful of the political sensitivities of the parties involved. Second, though pressure from the top, via federal government involvement, could prove useful in promoting more efficient transfer across Canada, it certainly is not enough. Constructing a robust transfer system requires commitment from across various levels. As Fazekas and Field (2013) point out, it requires adequate support and counseling for students at both sending and receiving institutions, articulation policies that are faithfully enacted by all players, and a range of other complementary structures at the organizational level (see pp. 51-52). As such, achieving the end goal of an efficient transfer system will truly require buyin from players at multiple levels. Federal intervention would thus be a positive, but not individually sufficient, step towards an improved transfer system.

\section{Acknowledgements}

The authors would like to thank the anonymous reviewers and journal editor for their thoughtful feedback on an earlier version of this manuscript.

\section{References}

Álvarez-Galván, J.-L., Field, S., Kuczera, M., Musset, P.,
\& Windisch, H. (2015). A skills beyond school commentary on Canada - OECD reviews of vocational education and training. Organisation for Economic Co-operation and Development. https://www.oecd. org/education/a-skills-beyond-school-commentary-on-canada.pdf

Arnold, C. (2011). Following the Ontario transfer student: From college to university inception. Canadian Society for the Study of Higher Education - Professional File, 31, 1-19. https://files.eric.ed.gov/fulltext/ ED535136.pdf

Arntz, M., Gregory, T., \& Zierahn, U. (2016). The risk of automation for jobs in OECD countries. Organisation for Economic Co-operation and Development. https://doi.org/10.1787/5j|z9h56dvq7-en

Brown, L. (2016, November 28). Transferring credits between college and university can be rocky. Macleans. https://www.macleans.ca/education/college/ transferring-credits-between-college-and-university-can-be-rockyl

Byrnes, J., Paez, D., Blacker, J., Jackson, A., \& Dwyer, C. (2011). The corporate strategy approach to articulation and credit transfer. DEEWR Diversity and Structural Adjustment Project. https://eprints. usq. edu.au/20414/1/Corporate-Strategy.pdf

Cameron, D. M. (2001). Postsecondary education and Canadian federalism: Or how to predict the future. Canadian Journal of Higher Education, 31(3), 143155. https://search-proquest-com.myaccess.library. utoronto.ca/docview/221135413?accountid=14771

Coburn, C. E. (2004). Beyond decoupling: Rethinking the relationship between the institutional environment and the classroom. Sociology of Education, 77(3), 211-244. https://doi. org/10.1177/003804070407700302

Council of Ministers of Education, Canada (CMEC). (1995). Pan-Canadian protocol on the transferability of university credits. https://www.cmec.ca/Publications/Lists/Publications/Attachments/198/Pan-Canadian-Protocol-Transferability-University-Credits.pdf

Council of Ministers of Education, Canada (CMEC). (2002). Ministerial statementon credit transfer in Canada. https://www.cmec.ca/Publications/Lists/ 
Publications/Attachments/193/winnipeg2002.en.pdf

Council of Ministers of Education, Canada (CMEC). (2012). Report of the CMEC credit transfer working group. https://www.cmec.ca/Publications/Lists/ Publications/Attachments/311/CTWG Report 2012 EN.PDF

Council of Ontario Universities. (2020). Key performance indicators, degree completion rate for undergraduate cohort, new year 1 students. https://cudo. ouac.on.ca/page.php?id=7\&table=22\#univ=1,2,3,8,9 $, 11,12,14,16,17,21,22,23,24,25,27,28,29,30,31,32,3$ $3,34,42 \&$ topic $=K \&$ table hidden $=5 \& r=1463 \& y=2015$

Cukier, W. (2019). Disruptive processes and skills mismatches in the new economy. Journal of Global Responsibility, 10(3), 211-225. https://doi.org/10.1108/ JGR-11-2018-0079

Desire to Learn. (2018). The future of skills. D2L. https:/l www.d2l.com/wp-content/uploads/2019/01/The-Future-of-Skills-Whitepaper-1.pdf

Dowd, A. C., \& Melguizo, T. (2008). Socioeconomic stratification of community college transfer access in the 1980s and 1990s: Evidence from HS\&B and NELS. The Review of Higher Education, 31(4), 377-400. https://doi.org/10.1353/rhe.0.0004

Duklas, J., Maki, K., Pesaro, J., \& Brady, J.-A. (2014). ARUCC PCCAT transcript and transfer credit nomenclature study - An examination of current practices at Canadian postsecondary organizations. Association of Registrars of the Universities and Colleges of Canada and the Pan-Canadian Consortium on Admissions \& Transfer. https://www.arucc. ca/uploads/documents/arucc pecat 15 jun 2014 english.pdf

Eastman, J., Jones, G. A., Bégin-Caouette, O., Noumi, C., \& Trottier, C. (2019). Federalism and university governance in Canada. Canadian Public Administration, 62(2), 333-335. https://doi.org/10.1111/ capa. 12319

Espeland, W. N., \& Sauder, M. (2007). Rankings and reactivity: How public measures recreate social worlds. American Journal of Sociology, 113(1), 1-40. https://doi.org/10.1086/517897

European Commission. (2019). Report of the high-level group on the impact of digital transformation on EU labour markets. https://ec.europa.eu/newsroom/dae/ document.cfm?doc id $=58412$

Fazekas, M., \& Field, S. (2013). A skills beyond school review of Germany - OECD review of education and training. Organisation for Economic Co-operation and Development. https://doi. org/10.1787/9789264202146-en

Field, S., \& Kuczera, M. (2012). A skills beyond school commentary on Israel. Organisation for Economic Co-operation and Development. https://www.oecd. org/education/skills-beyond-school/A Skills Beyond School Commentary on Israel.pdf

Field, S., Musset, P., \& Álvarez-Galván, J.-L. (2014). A skills beyond school review of South Africa. Organisation for Economic Co-operation and Development. http://www.oecd.org/education/skills-beyondschool/ASkillsBeyondSchoolReviewOfSouthAfrica. pdf

Fincher, M. (2002). Private university and community college strategic alliances: The case for co-operation. Community College Journal of Research and Practice, 26(4), 349-361. https://doi. org/10.1080/106689202753546493

Finnie, R., Dubois, M., \& Miyairi, M. (2020). Schooling and labour market outcomes of Ontario transfer students: Evidence from PSE-Tax linked data. Ontario Council on Articulation and TransfeR.

Frenette, M. (2019a). Do youth from lower- and higher-income families benefit equally from postsecondary education? Statistics Canada. https://www150.statcan.gc.ca/n1/en/ pub/11f0019m/11f0019m2019012-eng.pdf?st=WPFAGb21

Frenette, M. (2019b). Obtaining a bachelor's degree from a community college: Earnings outlook and prospects for graduate studies. Statistics Canada. https://www150.statcan.gc.ca/n1/en/ pub/11f0019m/11f0019m2019016-eng.pdf?st=Tv0NZZ-p

Frey, C. B., \& Osborne, M. A. (2017). The future of employment: How susceptible are jobs to computerisation? Technological Forecasting and Social 
Change, 114, 254-280. https://doi.org/10.1016/j. techfore.2016.08.019

Gerhardt, K., \& Masakure, O. (2016). Postsecondary student mobility from college to university: Academic performance of students. Canadian Journal of Higher Education, 46(2), 78-91.

Giani, M. S., Attewell, P., \& Walling, D. (2019). The value of an incomplete degree: Heterogeneity in the labor market benefits of college non-completion. The Journal of Higher Education, 91(4), 1-26. https://doi. org/10.1080/00221546.2019.1653122

Handel, S., \& Strempel, E. (2016). Transition and transformation: Fostering transfer student success. National Institute for the Study of Transfer Students.

Heath, N. (2012). Student mobility in Canada across Canadian jurisdictions: 2007/08 to 2009/10. Nick Heath Consulting Services. https://pccat.ca/media/1244/pccat mainreport final-en-full-documentwith-logos.pdf

Ignash, J. (1992). In the shadow of baccalaureate institutions. ERIC Clearinghouse for Junior Colleges. https://eric.ed.gov/?id=ED348129

Ithaca Group. (2018). Credit pathways in VET and higher education - Research project. https://docs. education.gov.au/system/files/doc/other/agfcreditpathways.pdf

Jenkins, P., \& Fink, J. (2015). What we know about transfer. Community College Research Center, Columbia University. https://academiccommons. columbia.edu/doi/10.7916/D8R218ZS/download

Jones, G. A. (2018). Decentralization, provincial systems, and the challenge of equity: High participation in higher education in Canada. In B. Cantwell, S. Marginson, \& A. Smolentseva (Eds.), High participation systems of higher education (pp. 203-226). Oxford University Press.

Junor, S., \& Usher, A. (2008). Student mobility \& credit transfer: A national and global survey. Educational Policy Institute. https://files.eric.ed.gov/fulltext/ ED529950.pdf

Labour Market Information Council. (2019). Annotated bibliography | future of work. https://Imic-cimt.cal
wp-content/uploads/2019/10/LMIC -Future of Work-Annotated Bibliography v2-5 oct2019-V2.pdf

Lamb, C. (2016). The talented Mr. Robot - The impact of automation on Canada's workforce. Brookfield Institute. https://brookfieldinstitute.ca/wp-content/ uploads/TalentedMrRobot BIIE-1.pdf

Lamb, C., Huynh, A., \& Vu, V. (2019). Lost and found: Pathways from disruption to employment. Brookfield Institute. https://brookfieldinstitute.ca/wp-content/ uploads/Lost-and-Found-ONLINE-2.pdf

Manyika, J., Lund, S., Chui, M., Bughin, J., Woetzel, J., Batra, P., Ko, R., \& Sanhvi, S. (2017). Jobs lost, jobs gained: Workforce transitions in a time of automation. McKinsey \& Company. https://www.mckinsey. com/featured-insights/future-of-work/jobs-lost-jobsgained-what-the-future-of-work-will-mean-for-jobsskills-and-wages\#

McCloy, U., Steffler, M., \& Decock, H. (2017). The changing patterns of college-to-university transfer: Examination of Ontario's Graduate Satisfaction Survey 2007-2015. Centre for Research in Student Mobility, Seneca College. https://www.senecacollege.ca/mobilityresearch/reports/The-Changing-Patterns-of-College-to-University-Transfer.pdf

Monaghan, D. B., \& Attewell, P. (2015). The community college route to the bachelor's degree. Educational Evaluation and Policy Analysis, 37(1), 70-91. https://doi.org/10.3102/0162373714521865

Monahan, E. J. (2004). Collective autonomy: A history of the Council of Ontario Universities, 1962-2000. Wilfrid University Press.

National Student Clearinghouse Research Center. (2019). Some college, no degree -A 2019 snapshot for the nation and 50 states. https://nscresearchcenter.org/wp-content/uploads/SCND Report 2019.pdf

NSW Business Chamber. (2010). The future of the VET system submission to skills Australia. https://www. nswbusinesschamber.com.au/NSWBC/media/ Policy/Workplace Skills/Future-of-the-VET-SystemSkills-Australia-submission-Nov-2010.pdf

Office of Program Policy Analysis \& Government Accountability. (2009). Education data warehouse serves important function; project planning and 
management need strengthening. http://www.oppaga.state.fl.us/MonitorDocs/Reports/pdf/0931rpt.pdf

Oliver, C. (1991). Strategic responses to institutional processes. Academy of Management Review, 16(1), 145-179. https://doi.org/10.5465/ AMR.1991.4279002

Ontario Council on Articulation and Transfer (ONCAT). (2020). 2+2 pathways in Ontario: An exploratory analysis [Unpublished Report].

Ontario Ministry of Colleges and Universities. (2019). Key performance indicators, colleges and other public institutions. http://www.tcu.gov.on.ca/pepg/ audiences/colleges/colindicator.htm|\#gr

Organisation for Economic Co-operation and Development (OECD). (2010). Higher education in regional and city development: State of Veracruz, Mexico. https://doi.org/10.1787/9789264089013-en

Organisation for Economic Co-operation and Development (OECD). (2012). OECD economic surveys: Canada 2012. https://doi.org/10.1787/eco surveyscan-2012-en

Organisation for Economic Co-operation and Development (OECD). (2014). Skills beyond school. https:/l doi.org/10.1787/9789264214682-en

Organisation for Economic Co-operation and Development (OECD). (2019). The future of work - OECD employment outlook 2019. https://www.oecd.org/ employment/Employment-Outlook-2019-Highlight-EN.pdf

Organisation for Economic Co-operation and Development (OECD). (2020). Preparing for the future of work in Canada. http://www.oecd.org/publications/preparing-for-the-future-of-work-in-canada05c1b185-en.htm

Paez, D., Jackson, A., Byrnes, J., Dwyer, C., \& Blacker, J. (2011). Articulation: A clearer picture or a new view? A DEEWR Diversity and Structural Adjustment Project. https://eprints.usq.edu.au/20411/1/ Artic Clearer Pic or New View.pdf

PhillipsKPA. (2006). Giving credit where credit is due. Department of Education, Science and Training. http://www.educationcouncil.edu.au/site/DefaultSite/
filesystem/documents/Reports and publications/Archive Publications/Higher Ed/Giving Credit Where Credit is Due.pdf

Pizarro Milian, R. (2018). Differentiating universities: Some insights from organization studies. Policy Reviews in Higher Education, 2(1), 79-104. https:/l doi.org/10.1080/23322969.2017.1396556

Rivera, L. (2011). Ivies, extracurriculars, and exclusion: Elite employers' use of educational credentials. Research in Social Stratification and Mobility, 29(1), 71-90. https://doi.org/10.1016/j.rssm.2010.12.001

Roksa, J., \& Keith, B. (2008). Credits, time, and attainment: Articulation policies and success after transfer. Educational Evaluation and Policy Analysis, 30(3), 236-254. https://doi. org/10.3102/0162373708321383

Schoenherr, J. R., \& Williams-Jones, B. (2016). Early contributions to the evolution of the Canadian scientific integrity system: Institutional and governmental interaction in the policy diffusion process. Canadian Journal of Higher Education, 46(1), 57-75.

Schwab, K., \& Samans, R. (2016). The future of jobs: Employment, skills and workforce strategy for the Fourth Industrial Revolution. World Economic Forum. http://www3.weforum.org/docs/WEF Future of Jobs.pdf

Senate Select Committee on the Future of Work and Workers. (2018). Hope is not a strategy - Our shared responsibility for the future of work and workers. Commonwealth of Australia. https://www. aph.gov.au/ /media/Committees/future of work and workers ctte/report.pdf?la=en

Shanahan, T., \& Jones, G. A. (2007). Shifting roles and approaches: Government coordination of postsecondary education in Canada, 1995-2006. Higher Education Research \& Development, 26(1), 31-43. https://doi.org/10.1080/07294360601166794

Shapiro, D., Dundar, A., Huie, F., Wakhungu, P.K., Yuan, X., Nathan, A. \& Hwang, Y. (2017). Tracking transfer: Measures of effectiveness in helping community college students to complete bachelor's degrees (Signature Report No. 13). National Student Clearinghouse Research Center. 
Simone, S. A. (2014). Transferability of postsecondary credit following student transfer or coenrollment (NCES 2014-163). National Center for Education Statistics. https://nces.ed.gov/pubs2014/2014163. pdf

Snowdon, K., \& Brady, J.-A. (2014). Towards a better understanding of credit transfer costs and benefits. Snowdon and Associates. http://snowdonandassociates.ca/wp-content/uploads/2018/06/ Towards-a-Better-Understanding-of-Credit-Transfer-Costs-and-Benefits.pdf

Trick, D. (2013). College-to-university transfer arrangements and undergraduate education: Ontario in a national and international context. Higher Education Quality Council of Ontario. http://www.heqco.cal SiteCollectionDocuments/Transfer Arrangements Trick ENG.pdf

University of Guelph. (1996). Senate memorandum - Pan-Canadian protocol on the transferability of university credits. https://uoguelph.civicweb.net/ document/35964

Weingarten, H., Hicks, M., Chatoor, K., MacKay, E., \& Pichette, J. (2019). Postsecondary education metrics for the 21st century. Higher Education Quality Council of Ontario. http://www.heqco.ca/SiteCollectionDocuments/Formatted Metrics for the 21st Century FINAL.pdf

York University. (1995). The Pan-Canadian protocol on the transferability of university credits. https://secretariat-policies.info.yorku.ca/policies/the-pan-canadian-protocol-on-the-transferability-of-university-credits/

\section{Contact Information}

\author{
Roger Pizarro Milian \\ rogerpizarro.milian@utoronto.ca
}

how to mitigate such effects. In the same year, the Australian senate also established a committee on the Future of Work and Workers to perform a similar task (see Senate Select Committee on the Future of Work and Workers, 2018).

2 It is important to note that, even in U.S. state systems with robust articulation systems, many transfer students do not graduate within four years for an array of reasons. Indeed, the six-year graduation rate for American community college students who transfer into a 4-year university has been found to be roughly $42.2 \%$ (Shapiro et al., 2016).

3 Despite the relative success and maturity of these transfer systems, we are not presenting them as finished products. Rather, we draw attention to them exhibiting qualities which could be usefully emulated by other jurisdictions. We do not explore the Quebec system through this piece given its distinctiveness, as students in that province are required to attend a CEGEP in order to gain admission into a university.

4 Other principles within the CMEC Ministerial statement have also failed to translate into effective practice or policies, including the idea that students should be provided with a rationalization for the refusal of transfer credit; the notion that learning experiences can be equivalent despite how courses are delivered; and lastly, that students should not be disadvantaged by the credit transfer process. Anecdotally, we know that students often do not get transfer credit assessments automatically and may not know results until they have enrolled or started classes; online courses are at times treated differently than in-person courses; and, transfer students often receive far less transfer credit than they should be entitled to.

5 Here, again, PLAR could play an important role in reducing unnecessary duplication of learning, as our hypothetical computer programmer could have management or some other type of relevant on the job experience.

6 For example, in Ontario, neither the college or university graduate surveys randomly sample graduates.

\section{Notes}

1 For example, the European Commission (2019) convened a group of high-level experts in 2018 to analyze the likely impact of digital transformations on the European labour market, and provide recommendations on 